\title{
Neutralizing Antibodies to Severe Fever with Thrombocytopenia Syndrome Virus 4 Years after Hospitalization, China
}

\section{Yu-ting Huang, Li Zhao, Hong-ling Wen, Yi Yang, Hao Yu, Xue-jie Yu}

Severe fever with thrombocytopenia syndrome is an emerging hemorrhagic fever disease in eastern Asia, caused by a tickborne bunyavirus. Of 25 patients hospitalized with this disease in China, $100 \%$ produced and maintained neutralizing antibodies to severe fever with thrombocytopenia syndrome virus for the study period of 4 years.

Severe fever with thrombocytopenia syndrome (SFTS) $\mathcal{N}$ is an emerging hemorrhagic fever disease in eastern Asia (1-3). SFTS is caused by SFTS virus (SFTSV), a tickborne bunyavirus that is transmitted through tick bites $(1,3,4)$ and person to person by contact with patient blood $(5,6)$. Clinically, SFTS is characterized by a sudden onset of fever, thrombocytopenia, hemorrhagic tendency, gastrointestinal symptoms, and multiple organ dysfunction and a high case-fatality rate of $12 \%-30 \%(1)$. SFTSV is a relatively new bunyavirus, and information regarding its neutralizing antibodies is scarce. In this study, we determined the prevalence and duration of neutralizing antibodies in serum samples of SFTS patients in China.

\section{The Study}

For this study, patients with a clinical diagnosis of SFTS were those who had fever, thrombocytopenia, or leukopenia without another known acute infectious disease; patients with laboratory-confirmed SFTS had SFTSV antibodies or RNA detected by ELISA or reverse transcription PCR (RT-PCR). Acute-phase (within 2 weeks after onset of illness) and convalescent-phase serum samples obtained during hospitalization of the patients were tested for total antibodies against SFTSV by using a double-antigen sandwich ELISA kit (Xinlianxin Biomedical Technology Limited, Wuxi, China). The study was approved by the ethics committee of Shandong University. Informed consent was obtained from all participants.

Author affiliations: Shandong University, Jinan, China

(Y.-T. Huang, L. Zhao, H.-L. Wen, Y. Yang, X.-J. Yu); Fudan

University, Shanghai, China (H. Yu); University of Texas Medical

Branch, Galveston, Texas, USA (X.-J. Yu)

DOI: http://dx.doi.org/10.3201/eid2211.160414
The ELISA plates were coated with recombinant SFTSV nucleoprotein (7). Undiluted patient serum samples were used for ELISA; SFTSV antibodies were detected with horseradish peroxidase-labeled recombinant SFTSV protein. Serum samples were considered positive for SFTSV when absorbance of the sample was $>2.1$ times that of a negative control at $450 \mathrm{~nm}(8)$. Nested RT-PCR amplification of the SFTSV RNA large segment (900 bp) and small segment (600 bp) have been described previously (8). PCR products were confirmed to be SFTSV RNA by DNA sequencing.

During June 26, 2011-August 26, 2012, a total of 46 patients were hospitalized and given a clinical diagnosis of SFTS in a local hospital in Yiyuan County, Shandong Province, China. We confirmed by ELISA or RT-PCR that $33(71.7 \%)$ of these 46 patients were infected with SFTSV. Of the confirmed cases of SFTS, 22 occurred in 2011 and were reported previously $(8)$. Two $(6.1 \%)$ patients with confirmed SFTS died.

Among the 31 laboratory-confirmed living patients with SFTS, 25 agreed and 6 refused to donate blood samples for neutralization assay after discharge. Thirteen (52\%) volunteers were male and 12 (48\%) were female; their ages ranged from 42 to 75 years (median age 62 years).

Blood samples were obtained from the 25 SFTS volunteers 2 or 3 times during a 4-year period. Serum samples were heat inactivated at $56^{\circ} \mathrm{C}$ for $30 \mathrm{~min}$ and diluted in 2-fold increments from 1:5 to 1:1,280. Each dilution of serum was mixed with an equal volume of solution containing SFTSV $(1,000 \mathrm{pfu} / \mathrm{mL})$ at $37^{\circ} \mathrm{C}$ for 1 hour. Culture medium was used as a control for serum. Samples were tested by using the $50 \%$ plaque reduction neutralization test $\left(\mathrm{PRNT}_{50}\right)$. The titer obtained is the reciprocal of the highest serum dilution that reduces the number of plaques by $50 \%$ relative to the average number of plaques in viral control wells.

At first, SFTSV does not form clear plaques on Vero cells. SFTSV is passaged on Vero cells until plaques are clearly visible. Initially, $10^{6} \mathrm{SFTSV}$ is inoculated into cells in 1 well of a 6-well plate. When a cytopathic effect is visible, cells with the cytopathic effect are aspirated with a pipette tip and transferred to a new well. A single plaque is picked and used for viral stock when the plaques are clearly visible on the fifth passage.

To determine the viral titer with a plaque assay, the viral stock is diluted from $10^{-2}$ to $10^{-6}$ in 10 -fold increments. 
Each dilution of viral stock is used to infect 2 wells of cells. (The negative control contains maintenance medium without virus.) Infected cells are incubated at $37^{\circ} \mathrm{C}$ in $5 \% \mathrm{CO}_{2}$ for $1 \mathrm{~h}$; then, viral inoculum is replaced with Dulbecco's modified Eagle medium containing 1.5\% methylcellulose, $1 \%$ fetal bovine serum, $10 \mathrm{mmol} / \mathrm{L}$ HEPES, penicillin (100 units $/ \mathrm{mL})$, and streptomycin $(100 \mu \mathrm{g} / \mathrm{mL})$. Plates are incubated at $37^{\circ} \mathrm{C}$ in $5 \% \mathrm{CO}_{2}$ for $10 \mathrm{~d}$. The monolayer is fixed with $4 \%$ paraformaldehyde and stained with crystal violet. Plaques in each well are counted to determine the plaqueforming unit.

$\mathrm{PRNT}_{50}$ results showed that all 25 patients developed neutralizing antibodies against SFTSV at titers from 20 to 640; the neutralizing antibodies lasted for the entire study period of 4 years (Table). We also performed $\mathrm{PRNT}_{90}$ tests for all 25 patients; these showed similar results to $\mathrm{PRNT}_{50}$, but the titers were less in extent than those of $\mathrm{PRNT}_{50}$ (data not shown).

In general, the titer of neutralizing antibodies decreased over time in all but 2 patients (nos. 5 and 11), who had a higher $\mathrm{PRNT}_{50}$ titer in the last year than in the first year; this increase may have been caused by reinfection with SFTSV. However, our previous studies indicate that, in the local area, the incidence of SFTSV infection is $<5$

Table. Neutralizing antibody titers for convalescent-phase serum samples from 25 patients with SFTS, Yiyuan County, Shandong, China, 2011-2014*

\begin{tabular}{|c|c|c|c|c|}
\hline \multirow[b]{2}{*}{ Patient no. } & \multicolumn{4}{|c|}{ Titer by PRNT $_{50}$} \\
\hline & First year & Second year & Third year & Fourth year \\
\hline 1 & 640 & NT & 320 & 80 \\
\hline 2 & 80 & NT & 40 & 80 \\
\hline 3 & NT & NT & 40 & 40 \\
\hline 4 & 20 & NT & 40 & 40 \\
\hline 5 & 20 & NT & 40 & 40 \\
\hline 6 & 80 & NT & 80 & 20 \\
\hline 7 & 40 & NT & 80 & 40 \\
\hline 8 & 5 & NT & 20 & 40 \\
\hline 9 & 40 & NT & 40 & 20 \\
\hline 10 & 160 & NT & 80 & 80 \\
\hline 11 & 160 & NT & 20 & 80 \\
\hline 12 & 160 & NT & 40 & 40 \\
\hline 13 & 40 & NT & 20 & NT \\
\hline 14 & NT & NT & 320 & NT \\
\hline 15 & 160 & NT & 160 & 80 \\
\hline 16 & 320 & NT & 40 & 40 \\
\hline 17 & 160 & NT & 40 & 40 \\
\hline 18 & NT & NT & 80 & 40 \\
\hline 19 & 640 & NT & 160 & 160 \\
\hline 20 & 320 & 80 & 80 & NT \\
\hline 21 & 640 & 320 & 80 & NT \\
\hline 22 & 20 & 20 & 20 & NT \\
\hline 23 & 320 & 80 & NT & NT \\
\hline 24 & NT & 80 & 40 & NT \\
\hline 25 & 640 & 80 & 160 & NT \\
\hline
\end{tabular}

*Convalescent-phase serum samples were obtained during the first, second, third, and fourth years after discharge of the patients from the hospital. NT, no test performed because serum was not available; PRNT 50 , plaque reduction neutralization test indicating the serum titer that reduced $50 \%$ of plaque-forming units of SFTS virus; SFTS, severe fever with thrombocytopenia syndrome. cases $/ 100,000$ population and the seroprevalence rate of SFTSV in the healthy population is $<1 \%(8-10)$, suggesting that the chance of reinfection of a patient with SFTSV is low. We cannot exclude, however, that these 2 patients could have been infected with other phleboviruses that have not yet been isolated in China. Serum samples from 2 healthy persons were also tested for neutralizing antibodies as controls; neither of them had any neutralization activity against SFTSV.

\section{Conclusions}

We found that hospitalized patients with SFTS produced long-lasting neutralizing antibodies to SFTSV. We do not know the characteristics of the neutralizing antibodies against SFTSV, which need to be further investigated. In general, neutralizing antigens of bunyavirus are located on the viral glycoproteins (11-13). A neutralizing monoclonal antibody to SFTSV is found to bind a linear epitope in the ectodomain of glycoprotein Gn of SFTSV. Its neutralizing activity is attributed to blockage of the interactions between the Gn protein and the cellular receptor (14). The limitation of this study is that we obtained SFTS patients' serum samples for only up to 4 years after diagnosis; we do not know how long the neutralizing antibodies in patients will last.

This study was supported by grants from Shandong Province Science and Technology Development Program (no.

2014GSF121004) and National Natural Science Funds of China (nos. 31570167 and 81102171).

Ms. Huang is a doctoral student at Shandong University in Jinan City, China, studying the molecular epidemiology of tick-borne emerging infectious diseases.

\section{References}

1. Yu XJ, Liang MF, Zhang SY, Liu Y, Li JD, Sun YL, et al. Fever with thrombocytopenia associated with a novel bunyavirus in China. N Engl J Med. 2011;364:1523-32. http://dx.doi.org/10.1056/ NEJMoa1010095

2. Kim WY, Choi W, Park SW, Wang EB, Lee WJ, Jee Y, et al. Nosocomial transmission of severe fever with thrombocytopenia syndrome in Korea. Clin Infect Dis. 2015;60:1681-3. http://dx.doi.org/10.1093/cid/civ128

3. Takahashi T, Maeda K, Suzuki T, Ishido A, Shigeoka T, Tominaga T, et al. The first identification and retrospective study of severe fever with thrombocytopenia syndrome in Japan. J Infect Dis. 2014;209:816-27. http://dx.doi.org/10.1093/infdis/jit603

4. Luo LM, Zhao L, Wen HL, Zhang ZT, Liu JW, Fang LZ, et al. Haemaphysalis longicornis ticks as reservoir and vector of severe fever with thrombocytopenia syndrome virus in China. Emerg Infect Dis. 2015;21:1770-6. http://dx.doi.org/10.3201/ eid2110.150126

5. Bao CJ, Guo XL, Qi X, Hu JL, Zhou MH, Varma JK, et al. A family cluster of infections by a newly recognized bunyavirus in eastern China, 2007: further evidence of person-to-person transmission. Clin Infect Dis. 2011;53:1208-14. http://dx.doi.org/10.1093/cid/cir732 
6. Liu Y, Li Q, Hu W, Wu J, Wang Y, Mei L, et al. Person-to-person transmission of severe fever with thrombocytopenia syndrome virus. Vector Borne Zoonotic Dis. 2012;12:156-60. http://dx.doi.org/10.1089/vbz.2011.0758

7. Jiao Y, Zeng X, Guo X, Qi X, Zhang X, Shi Z, et al. Preparation and evaluation of recombinant severe fever with thrombocytopenia syndrome virus nucleocapsid protein for detection of total antibodies in human and animal sera by double-antigen sandwich enzymelinked immunosorbent assay. J Clin Microbiol. 2012;50:372-7. http://dx.doi.org/10.1128/JCM.01319-11

8. Wen HL, Zhao L, Zhai S, Chi Y, Cui F, Wang D, et al. Severe fever with thrombocytopenia syndrome, Shandong Province, China, 2011. Emerg Infect Dis. 2014;20:1-5. http://dx.doi.org/10.3201/ eid2001.120532

9. Zhao L, Zhai S, Wen H, Cui F, Chi Y, Wang L, et al. Severe fever with thrombocytopenia syndrome virus, Shandong Province, China. Emerg Infect Dis. 2012;18:963-5. http://dx.doi.org/10.3201/ eid1806.111345

10. Cui F, Cao HX, Wang L, Zhang SF, Ding SJ, Yu XJ, et al. Clinical and epidemiological study on severe fever with thrombocytopenia syndrome in Yiyuan County, Shandong Province, China. Am J Trop Med Hyg. 2013;88:510-2. http://dx.doi.org/10.4269/ ajtmh.11-0760
11. Hofmann H, Li X, Zhang X, Liu W, Kühl A, Kaup F, et al. Severe fever with thrombocytopenia virus glycoproteins are targeted by neutralizing antibodies and can use DC-SIGN as a receptor for $\mathrm{pH}$-dependent entry into human and animal cell lines. J Virol. 2013;87:4384-94. http://dx.doi.org/10.1128/JVI.02628-12

12. Takenaka A, Gibbs CJ Jr, Gajdusek DC. Antiviral neutralizing antibody to Hantaan virus as determined by plaque reduction technique. Arch Virol. 1985;84:197-206. http://dx.doi.org/10.1007/ BF01378972

13. Niklasson B, Peters CJ, Bengtsson E, Norrby E. Rift Valley fever virus vaccine trial: study of neutralizing antibody response in humans. Vaccine. 1985;3:123-7. http://dx.doi.org/10.1016/0264410X(85)90061-1

14. Guo X, Zhang L, Zhang W, Chi Y, Zeng X, Li X, et al. Human antibody neutralizes severe fever with thrombocytopenia syndrome virus, an emerging hemorrhagic fever virus. Clin Vaccine Immunol. 2013;20:1426-32. http://dx.doi. org/10.1128/CVI.00222-13

Address for correspondence: Xue-jie Yu, Department of Pathology, University of Texas Medical Branch, 301 Universitiy Boulevard, Galveston, TX 77555, USA; email: xuyu@utmb.edu

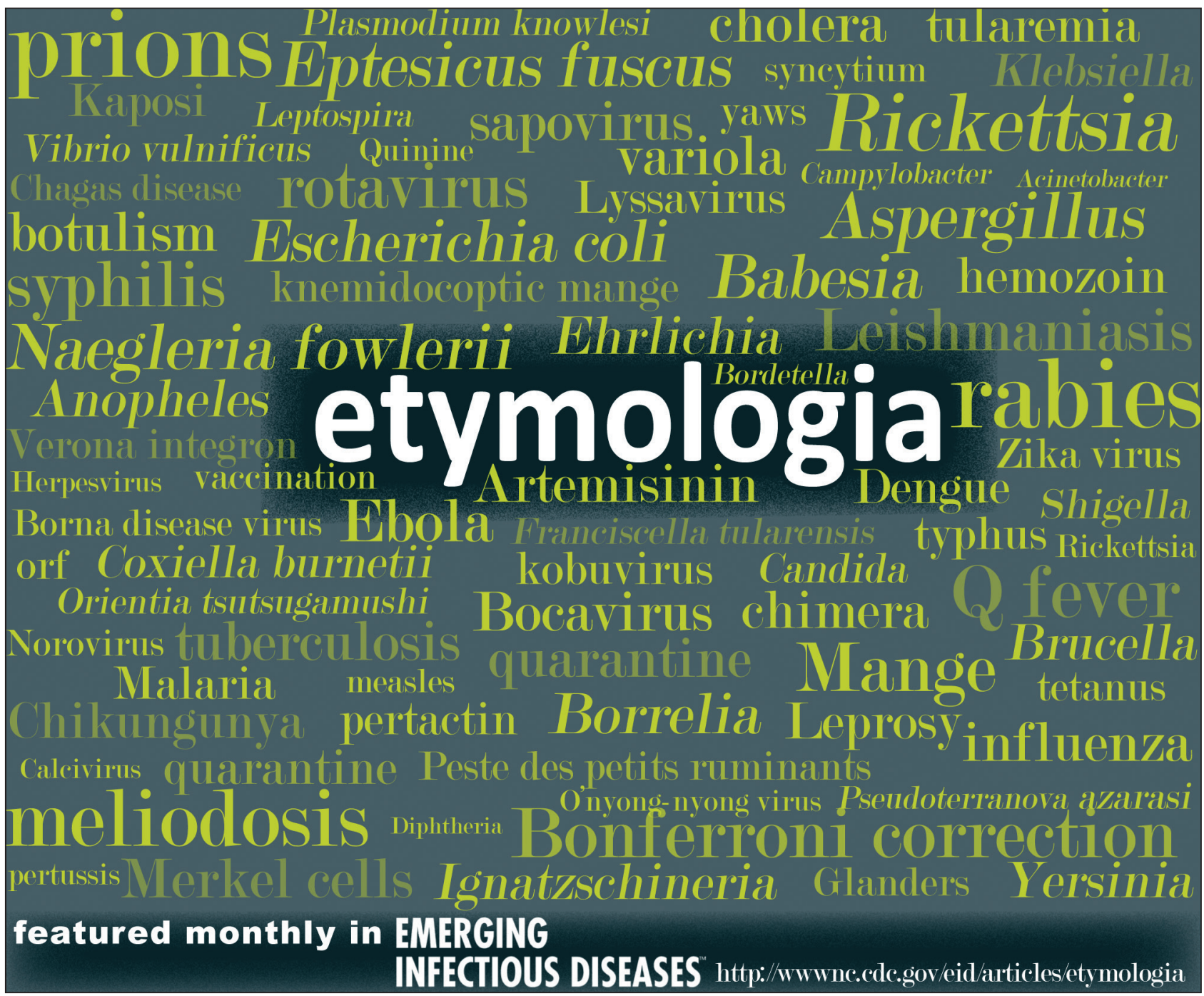

